\title{
Hypothesis of Early Development of Chicken Embryos
}

\author{
T. O. Azarnova, I. S. Yartseva*, A. E. Bobilkova
}

Moscow State Academy of Veterinary Medicine, Biotechnology Named by K.I. Skryabin

\begin{abstract}
In this work we set the following goal: to study the influence of a complex usage of such natural metabolites as Kolamin, succinic acid and Ribav upon the acceleration of chicken embrio development, as well as their hatching and viability indices. For the estimation of biochemical indices, standard methods were used, according to the data in the scientific literature (I.P.Kondrakhin, 1985; M.I.Prokhorova, 1982; V.V.Menshikov, 1987; B.I.Antonov, 1991). As a result we found that aerosol processing of incubational eggs by the complex of natural metabolites: ethanolamine, succinate and Ribav makes it possible to neutralize free radical reactions and lip id peroxidation and, as a result, the hypoenergetic conditions in the organism of the fowl, which produces an opportunity to correct the metabolic processes in the critical periods of fetal development. All this causes the optimization of internal homeostasis, and therefore mitigates the negative processes in these stages. In connection with that we can make a conclusion about an early development of chicken embrios, as well as about a positive influence of the metabolites under analysis upon the incubation biocontrol markers.
\end{abstract}

Keywords Chickens, Oxidative Stress, Lipid Peroxidation, Kolamin, Succinic Acid, Ribav, The Critical Periods of Incubation

\section{Introduction}

In the process of embryogenes is the aniage and formation of all organs, tissues and systems of the fowl take place. That is why this period is the most important in the life of a subject.

As is known, during some periods of incubation the mortality of embryos is especially high, which is determined by abrupt saltatory alterations in the organis m (for example, the switch from allantoic to lung respiration) that result in high tension and often even failure of many metabolic processes[6]. All this leads to excessive energetic expenses. Hypoenergetic statuses in these periods are to a great extent determined by a "breakdown" of the mitochondrial respiratory chain, due to which excessive production of free radicals and active oxygen forms takes place[2]. All this predetermines not only a high mortality rate but at least a deceleration of embryo development in the strongest organisms. The main periods in which these negative phenomena take place are called critical - they usually occur on the $4-5^{\text {th }}, 14-15^{\text {th }}$ and $19-20^{\text {th }}$ days of incubation[12]. Besides, when speaking about the reasons for mortality rise during these critical periods, many researchers associate them not only with the natural physiological reasons. They also link the first period to a long-time storage of the eggs prior to incubation or to their overheating at the beginning of

* Corresponding author:

ine98@yandex.ru (I.S. Yartseva)

Published online at http://journal.sapub.org/ajb

Copyright (C) 2012 Scientific \& Acad emic Publishing. All Rights Reserved it, the second one - to the low quality of incubational eggs (due to lack of vitamins and other nutrients) and the third one - to various disruptions of incubation conditions [14]. It is also pointed out that at the end of incubation the mortality rate is usually three times as high as at the beginning. The embryos dying in the critical periods are ascribed to the categories of incubational waste: the blood ring, the dead-in-shell and the addled eggs[1]. However, even if the chick outs tays these critical periods, they undoubtedly have a negative influence upon the embryo's development and formation, which, as was pointed out earlier, is directly connected with the increase of the incubation time, various pathologies in the development of organs, poor exterior characteristics of the fowl and a high mortality rate, especially during the first weeks of life [5].

\section{Objectives}

Thus, the aim of this work is to reveal the possibility of using the complex of metabolites: monoethanol amine, succinic acid and Ribav for the neutralization of free radical processes, lipid peroxidation and hypoenergetic statuses, with the main goal of correcting the critical periods of embryo develop ment.

Free radicals are produced in the organism even without any pathologies, having their own important purposes in the organism[7]. But together with a disruption of the general homeostasis and the influence of negative environmental factors, as well as the loss of nutrients and microelements, the elaboration of free radicals by the organism becomes many times higher, which causes the development of 
pathological processes in the organism of the embryo, later on having an effect on the viability and productivity of the adult organisms. Thus, one of the most valuable consequences of the excessive free radical synthes is is lipid peroxidation that leads to the cell membrane destabilization and the dysfunction of the cell[9].

\section{Methods}

To prevent the abovementioned conditions, we used the main component of the membrane phospholipids -monoethanol amine, which, through the trans formation into choline, can participate in the functioning of the mitochondrial respiratory chain[4]. It is important to point out that in order to make such transformations effective this biologicallyactive substance (BAS) needs the assistance of an energetic substrate[10]. Taking into account the experience of the previous researchers, a universal natural metabolite that is involved into the tricarboxylic acid cycle and the biological oxygenation was selected for this purpose - that is succinic acid, which, if necessary, can also be used by the organism in the synthesis of various substances [8]. Considering also the fact that when the peroxidation process is highly intensive there appear lipofuscins (Shiff's bases) made from malondialdehyde and other aldehydes with protein structures, which happens due to the dysfunction of the latter, it was decided to insert a multicomponent preparation Ribav that mostly consists of essential and noness ential amino acids. It is important to remember that for a growing organism that is subject to stress any mono mers of protein are ess ential[11].

\section{Results}

In a series of experiments we proved the possibility of using the complex of biological stimulators and elaborated the application scheme for ko lamin, succinic acid and Ribav by means of one-time aerosol processing of eggs before setting them for incubation.

For the research an experimental group and a control one were selected (306 eggs in each) by the principle of analogy taking into account the laying time, the weight, the age of the parental stock and the storage term.

Table 1. Indices of Lipid Peroxidation (LP) and the Antioxidant Defense System (ADS) (n=5)

\begin{tabular}{|c|c|c|c|c|}
\hline Group & $\begin{array}{c}\text { Peroxidase, } \\
\text { transmission } \\
\text { density } \\
\text { units } / 1^{*} \mathrm{sec}\end{array}$ & $\begin{array}{c}\text { Superoxide } \\
\text { dismutase, } \\
\text { act./mg of } \\
\text { gemoglobin } \\
\mathrm{e}\end{array}$ & $\begin{array}{c}\mathrm{SB}, \\
\text { relative } \\
\text { units } / \mathrm{ml}\end{array}$ & $\begin{array}{c}\text { MDA, } \\
\mathrm{mkmol} / 1\end{array}$ \\
\hline Control & $24 \pm 1.82$ & $1.0 \pm 0.25$ & $0.4 \pm 0.04$ & $1.7 \pm 0.08$ \\
\hline $\begin{array}{c}\text { Experi } \\
\text { mental }\end{array}$ & $50 \pm 2.49 * * *$ & $2.8 \pm 0.31 * *$ & $\begin{array}{c}0.2 \pm 0.03 \\
* *\end{array}$ & $\begin{array}{c}1.1 \pm 0.08 \\
* *\end{array}$ \\
\hline
\end{tabular}

Table 2. Biochemical Blood and Serum Markers of Day-old Chicks ( $n=5)$

\begin{tabular}{|c|c|c|}
\hline $\begin{array}{l}\text { Group } \\
\text { Marker }\end{array}$ & Control & Experimental \\
\hline Total protein, $\mathrm{g} / \mathrm{l}$ & $32.3 \pm 1.42$ & $35.0 \pm 0.7^{*}$ \\
\hline Glycine, $\mathrm{mcmol} / 1$ & $236 \pm 11.95$ & $283.4 \pm 51.93$ \\
\hline Uric acid, mmol/1 & $0.31 \pm 0.008$ & $0.35 \pm 0.012$ \\
\hline$\alpha$-globulines, $\%$ & $19.8 \pm 0.19$ & $20.7 \pm 1.19$ \\
\hline$\beta$-globulines, $\%$ & $12.4 \pm 1.34$ & $12.9 \pm 1.1$ \\
\hline$\alpha$-amylase, $\mathrm{u} / \mathrm{l}$ & $1080 \pm 92.7$ & $1242 \pm 51.12 *$ \\
\hline Glucose, mmol/1 & $9.36 \pm 0.08$ & $10.21 \pm 0.16$ \\
\hline $\mathrm{LDH}, \mathrm{u} / \mathrm{l}$ & $216 \pm 32.95$ & $270 \pm 21.51$ \\
\hline Pentoses, mmol/1 & $0.14 \pm 0.01$ & $0.20 \pm 0.01 * *$ \\
\hline Piruvic acid, mmol/1 & $0.09 \pm 0.01$ & $0.14 \pm 0.01 *$ \\
\hline Total lipids, g/l & $1.450 \pm 0.014$ & $1.564 \pm 0.03^{*}$ \\
\hline Phosphatidylcholine, mmol/1 & $2.1 \pm 0.13$ & $2.7 \pm 0.13^{*}$ \\
\hline $\mathrm{Ca}, \mathrm{mmol} / \mathrm{l}$ & $3.18 \pm 0.06$ & $3.31 \pm 0.07$ \\
\hline $\mathrm{P}, \mathrm{mmol} / \mathrm{l}$ & $2.03 \pm 0.07$ & $2.16 \pm 0.05$ \\
\hline Alkaline phosphatase, $\mathrm{u} / \mathrm{l}$ & $1227 \pm 15.16$ & $1330 \pm 11.92 *$ \\
\hline Lysozyme, mcg/ml & $35.7 \pm 0.4$ & $38.7 \pm 0.75 * *$ \\
\hline AKT H, ng/ml & $21 \pm 1.58$ & $21.4 \pm 5.16$ \\
\hline Cortisol, nmol/1 & $10.20 \pm 1.97$ & $10.06 \pm 5.73$ \\
\hline $\mathrm{T} 3, \mathrm{nmol} / \mathrm{l}$ & $1.78 \pm 0.13$ & $2.06 \pm 0.38$ \\
\hline
\end{tabular}


As we can see from the table, the intensity of lipid peroxidation in the experimental group is considerably lower than in the control one. Thus, the level of the secondary product of lipid pero xidation in the form of malondialdehyde (MDA) is 1.5 times lower, and the level of the final product of LP (the Shiff's bases) is 2 times lower. Taking into consideration the fact that excessive lip id peroxidation contributes to the decrease of the functional activity of the cells and is to a great extent connected with the dis ruption of the barrier and transfer functions of the membranes, which leads to changes in the cellho meostas is, the breakdown of its energy production and as a result to its death[13], it is possible to testify that the preparations under analysis are capable of effectively preventing the destruction of the phospholipid framework of the plasmolemma, thus averting the dysfunction and quite possibly the death of the cell. The positive effect of the preparations not only prevented the exhaustion of the enzymatic antioxidant system of the organism, but also stipulated its activation. Thus, the activity of superoxide dis mutase and peroxidase grew 2.8 and 2 times higher correspondingly in comparis on to the control group.

The correction of free radical process es and, consequently, of the lipid peroxidation intensity, contributed to the optimization of the metabolic processes in the organism of the chickens.

From the data shown in the table it is evident that the solutions of BAS described above, when used in a complex, contributed to the optimization of some metabolic processes, including protein metabolism (the level of general protein in the serum of the chickens in the experimental group is $8.4 \%$ higher that that in the control one). The $20 \%$ rise of the glycine level can also serve a good proof of the fact that Ribav, containing among other components aminoacetic acid, is really capable of penetrating into the egg and participating in the metabolic processes of the embryo. This statement can also be confirmed by the fact that the increase of the glycine level can not be realized by means of the organism's own reserves, because it would cause its rapid exhaustion and consequently lead to a pathological decrease in the intensity of metabolic processes. However, as the experiment demonstrates, such events do not happen.

Besides, a tendency towards the activation of carbohydrate metabolism can also be traced, which is seen from the rise of the $\alpha$-amy lase level to 1.2 times as much as in the control group and of that of glucose - by $9.1 \%$. It is worth mentioning that in connection with the increase of the levels of piruvic acid (1.6 times) and LDH (1.3 times), a conclusion can be made that both the aerobic and the anaerobic glycolysis are activated. The level of pentoses became 1.4 times higher, which resulted in a better correlation between the carbohydrate, protein and nucleic acid metabolis $\mathrm{m}$. It is evident that such interconnection can to a certain extent support the organism later on in stress situations, forming a possibility for compensatory functions in each type of metabolism, which is important for the expansion of the organism's adaptation resources $[3,15]$.
It is also important to point out the tendency towards changes in the hormone status, including stress hormones. Thus, it is revealed that the AKTH level in the experimental group is to some extent higher than in the control one, with a slight downfall of the level of cortisol. This evidently happens due to the fact that the process of glycogen synthes is becomes less intensive in the chickens of the experimental group. The increase in the triiodothyronine (T3) level, in its turn, is caused by the activation of metabolic processes including glycolisis, which is proved by the series of previous statements. Besides, taking into account the inverse correlation between AKTH and cortisol, me can make a conclusion about the optimization of the inner homeostas is in the organism of the experimental chickens, because under stress conditions the levels of AKTH and cortisol correlate directly[13]. Taking into consideration that hatching is a stress situation, it is possible to state that our conclusion is justified.

It is also important to pay attention to other regularities that can be traced in Table 2 . It can be seen that kolamin in the suggested mixture effectively integrates into thephospholipid complexes, which is evident first of all from the rise of the lecithin level 1.3 times higher. Consequently, under any stress influence, whether prognosticated or not, the organism of the chicken requires components of phospholipids in order to neutralize membrane destructions. And kolamin from our mixture satisfies this requirement to a considerable degree.

All this brings about an increase of the natural resistance of the chicken's organism, which is also confirmed by the rise of the lysozy me activity by $8.4 \%$.

\section{Discussion}

Thus we can suppose that the level and intensity of the metabolic processes and the tendencies traced in the experimental group are optimal, considering the fact that the experimental chickens are better developed and their viability is higher during a long period of life, whereas their embryonic development is shorter, at the same time being well-balanced.

All the abovementioned proves that the suggested mixture has a marked antioxidant and metabolism-stimulating property. Evidently this is what the embryo needs for a balanced development without any delay. This is confirmed by the data from Table 3 .

Table 3. Cat egories of Eggs according to the Degree of Allantoic Closure on the 11th Day, \% $(n=100)$

\begin{tabular}{|c|c|c|c|}
\hline $\begin{array}{c}\text { Group } \\
\text { Category } \\
\text { of eggs according } \\
\text { to allantois }\end{array}$ & 1 cat egory & 2 cat egory & $\begin{array}{c}3 \\
\text { category }\end{array}$ \\
\hline Control & 23.00 & 39.00 & 38.00 \\
\hline Experimental & 42.00 & 36.00 & 22.00 \\
\hline
\end{tabular}


Thus, on the 11th day, absolute closure of the allantois at the acute end was evident in more embryos from the experimental group than fro $m$ the control one. It can be seen from Table 3 that the first-category eggs from the experimental group outnumber those from the control group.

Besides, there is an important peculiarity in the fact that the saplings in the experimental group were not only more active but, what is more important, they hatched 1.5 days earlier than in the control group.

The graph shows that the hatching intensity of the experimental chickens was higher, and by the beginning of hatching in the control group, all the experimental saplings had already hatched.

The histogram of hatching intensity clearly demonstrates the fact that the chickens fro $m$ the experimental group switch to mass hatching almost immed iately after pecking (the peak is at 446 hours), whereas in the control group mass hatching requires more time (the peak is at 490 hours).

Greater viability of the e mbryos should also be mentioned. It can be seen from the increase of hatchability and the number of hatching eggs that outrun the control group by $9.26 \%$ and $10.46 \%$ correspondingly. Besides, in the experimental group mortality is 2 times lower.

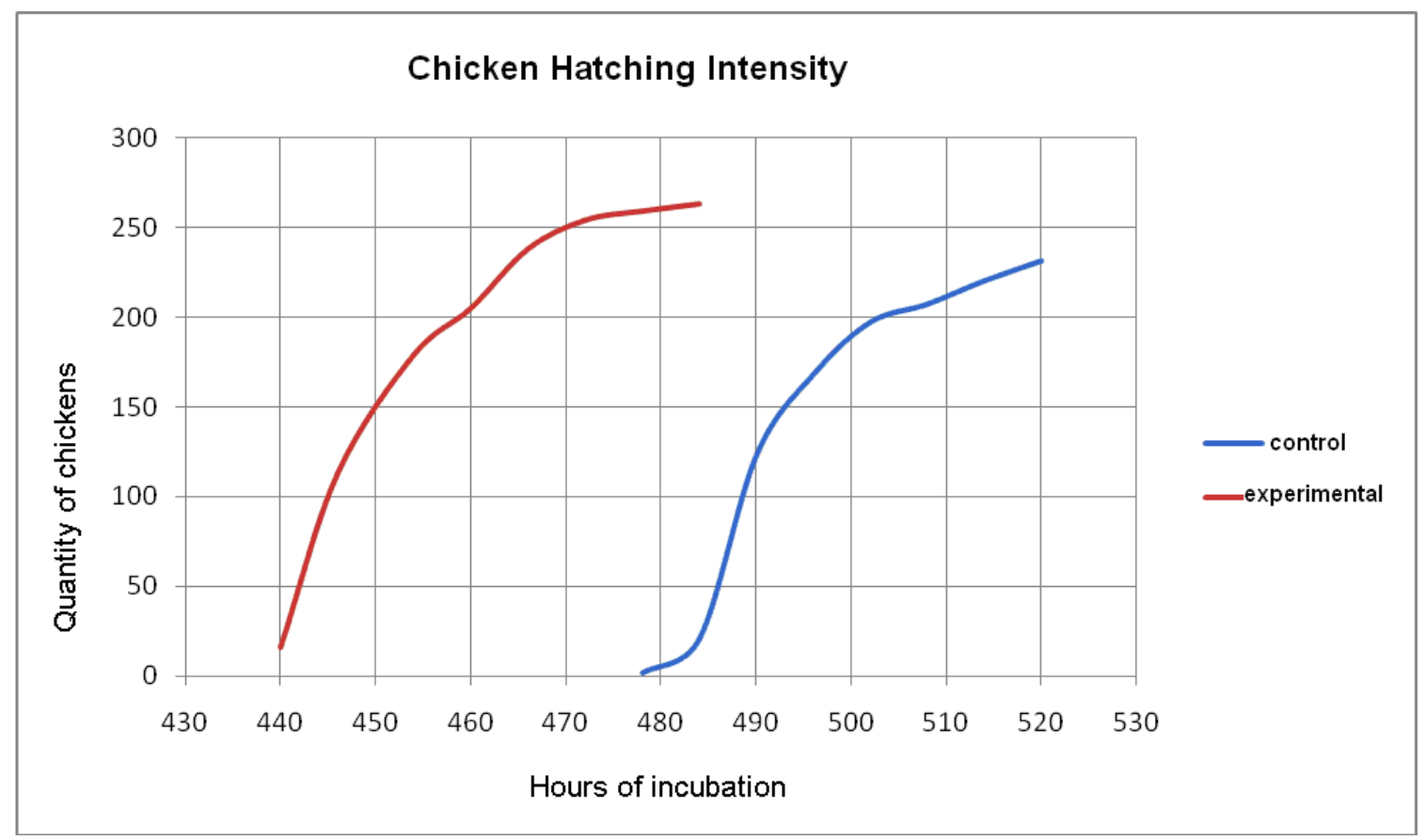

Figure 1. Hatching Intensity of Chickens

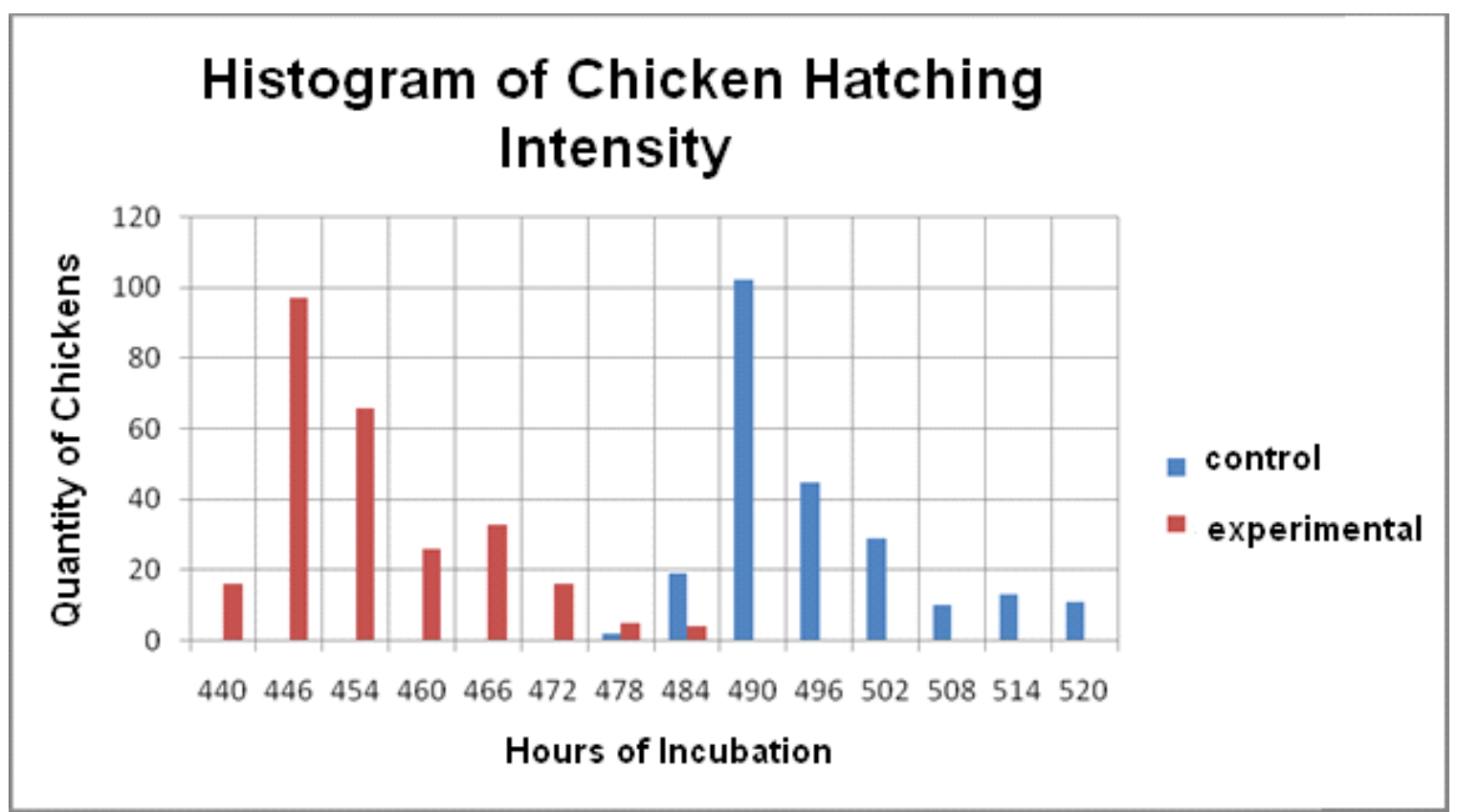

Figure 2. Histogram of Chicken Hatching Intensity 


\section{Conclusions}

Based upon all this, it is possible to suggest a hypothes is of earlier development of the embryos, due to the fact that, as our research shows, the complex of metabolites under analys is makes the process of embryogenes is 1.5 days faster. The embryogenes is of chickens (and probably of other living organisms) lasts longer than it is naturally determined. This happens due to simultaneous influence of various stress factors upon the organism of the embryo that cause destabilization of the homeostasis. Besides, there are critical periods in the process of embryogenesis in which the mortality rate is especially high. All this is a result of disruptions in many metabolic processes and of changes in their intensity. The latter lead to excessive energetic expences (in order to keep the homeostasis at the optimal level) as well as to full or partial loss of ATP in several processes[15]. The hypoenergetic statuses in these periods are to a great extent caused by the dysfunction of the mitochondrial respiratory chain, which leads to an excessive production of free radicals and active oxygen forms. This disturbs the biological oxygenation function and the metabolism as a whole, leading to hypoxia, deactivation of enzymes, destruction of receptors and hormones. All this undoubtedly slows down the development of stronger embryos and kills weaker ones[6]. The neutralization of free radical reactions and lip id peroxidation (and, as a result, the hypoenergetic statuses) makes it possible to correct the metabolic processes in the organism of the fowl not only during the main critical periods in the embryogenesis, but also in any stress situations, which keeps the inner homeostas is at the optimal level and, consequently, mitigates the negative processes. As a result, the organism of the chicken does not have to enlist all its efforts and to spend nutritional components on additional synthes is of ATP of which it did not receive enough due to disturbances in the functioning if the mitochondrial respiratory chain. All this enables the organism to shorten the terms of its embryogenesis in a natural way. It is worth mentioning that the metabolites under analys is can also be used for other bird species (the quail, the pelican and fancy hen breeds), as well as for the processing of plant seeds. Our latest research shows a high effectiveness of the metabolites for these biological objects. Taking this into consideration, we can conclude that the preparations under analys is can be widely used, due to the fact that the processes of biological oxygenation are identical both for the plants and the animals. Further on it can be possible to apply the worked out technologies for industrial poultry farming because it is economically justified.

\section{REFERENCES}

[1] Yermolova, Yu.S. Processing of Chicken Eggs by Biologically Active Substances for the Stimulation of Chickens' Resistance at Various Stages of Ontogenesis: Dissertation Abstract of Candidate of Biological Sciences// Moscow. - 2003. - p.23

[2] Zhuravlev, A.I. Antioxidants. Free Radical Pathology/ A.I.Zhuravlev, S.M.Zubkova// Moscow. - Moscow State Academy of Veterinary Medicine and Biotechnology named by K.I.Skry abin. - 2008. - 272 pp.

[3] Isyangulova, R.Kh. The Substance and Energy Metabolism and Meet Productivity of Bulls in case of Feeding them with Mitugen, Kolamin and their Complexes in Stress Periods: Dissertation Abstract of Candidate of A gricultural Sciences// Orenburg. $-2008 .-$ p. 20

[4] Kinyabulatova, R.Kh. The Usage of Feed Preparation Mival and Kolamin for the Correction of Stress Adaptation and the Increase in Raising Effectiveness of Meet-type Bulls: Dissertation Abstract of Candidate of A gricultural Sciences// Orenburg. $-2009 .-$ p. 25

[5] Krasnobaev, Yu.V. Processing of Eggs of Meet-type Hens by the Ecologically Safe Preparation Helavit for the Stimulation of Embryonal and Postembryonal Development of Broyler Chickens: Dissertation of Candidate of Biological Sciences// Moscow. - Moscow State Academy of Veterinary Medicine and Biotechnology named by K.I.Skryabin. - 2009. - p.147

[6] Karput, I.M., Babina, M.P. Inner Noncontagious Diseases of Fowl// Minsk/ Data Processing Computer Center "Minfina". $-2011 .-176 \mathrm{pp}$.

[7] Kukhta, V.K., Morozkina, T.S., Oletskiy, E.I. Biological Chemistry//Moscow/ BINOM. - 2008. - 687 pp.

[8] Marry, R., Grenner, D., Meyes, P. Human Biochemistry// Moscow/Mir. - 2009. - 129 pp.

[9] Marshall, V.J, Bangert S.K. Clinical Biochemistry. $-6^{\text {th }}$ ed., revised and updated. - Moscow/BINOM. - 2011. - 408 pp.

[10] Ottaway, P.B. Enrichment of Food Products and Biologically Active Substances: Technology, Safety and Regulatory System// St. Petersburg/ Professia. - 2010. - 312 pp.

[11] Severin, E.S. Biochemistry// Moscow/ GEOTAR-MEDIA. 2010. $-384 \mathrm{pp}$.

[12] Soldatova I.B. Development and Metabolism of Chicken Embryos in case of Sound Stimulation// Ontogen esis. 2011. Vol.42, 4.

[13] Tkachuk, V.A. Clinical Biochemistry. $-3^{\text {rd }}$ ed., revised and updated. -Moscow/ GEOTAR-MEDIA. - 2008. - 454 pp.

[14] Fisinin, V.I. Effective Defense against Stress in Poultry Farming: from Vitamins to Vitagens/ Fisinin, V.I., Surray, Peter// Fowl and Poultry Products// Moscow. - 2011, 5. pp.23-26.

[15] Yarovan, N.I. Biochemical Aspects of Evaluation, Diagnostics and Preventive Measures of Technological Stress in Agricultural Animals: Dissertation Abstract of Doctor of Biological Sciences// Moscow - 2008. - pp.3-39. 